Plant Tissue Cult. \& Biotech. 22(2): 171-177, 2012 (December)

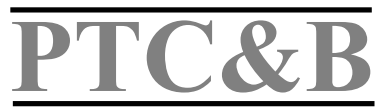

\title{
Influence of an Indirect Precursor on Podophyllotoxin Accumulation in Cell Suspension Cultures of Podophyllum hexandrum
}

\author{
Anrini Majumder* \\ Centre of Advanced Study, Department of Botany, University of Calcutta, \\ 35 Ballygunge Circular Road, Kolkata-700019, India \\ Key words: Indirect precursor, Podophyllotoxin, Podophyllum hexandrum
}

\begin{abstract}
Podophyllum hexandrum is an endangered, commercial source of a naturally occurring lignan podophyllotoxin, which is a precursor of potent anticancer drugs. Cell suspension cultures were established using four-year-old cell line RC4 of $P$. hexandrum in liquid P1 medium [half strength B5 basal medium supplemented with $1 \%(\mathrm{w} / \mathrm{v})$ sucrose, 2,4-D (1 mg/l), GA $3(1 \mathrm{mg} / \mathrm{l})$ and BA $(0.1$ $\mathrm{mg} / \mathrm{l})]$. The effect of different concentrations $(100,250$ and $500 \mathrm{mg} / \mathrm{l})$ of tryptophan, an indirect precursor of lignan biosynthesis, was studied on cell suspension cultures. Cultures accumulated 2.7 times more podophyllotoxin than untreated control cultures when treated with $250 \mathrm{mg} / \mathrm{l}$ tryptophan. Biomass yield was, however not improved following the addition of tryptophan.
\end{abstract}

\section{Introduction}

Podophyllotoxin (an aryl tetralin lignan) is a pharmaceutically active natural compound. It is widely used as a precursor for the semisynthesis of well-known antitumour drugs like etoposide (VP-16-213) and teniposide (VM-26) which are used in the treatment of lung cancer, testicular cancer, a variety of leukemias and other solid tumours (Holthius 1988, Stahelin and Wartburg 1991, Imbert 1998). But the availability of podophyllotoxin has become limited due to the dwindling nature of its commercial source Podophyllum hexandrum (Indian Podophyllum, Berberidaceae) which has already been categorized as a threatened species and low yielding, uneconomical chemical synthesis of the compound. The limited supply of podophyllotoxin from $P$. hexandrum has prompted intense efforts to develop alternate sources and means of production. Biotechnological approaches for the production of podophyllotoxin were first reported by Kadkade (1981) in

*Author for correspondence: <anrini2002@yahoo.co.in>. 
P. peltatum (American Podophyllum) and by Uden et al. (1989) in P. hexandrum callus cultures. Since then several studies have been carried out for improvement of podopyllotoxin accumulation in cell cultures of P. hexandrum (Uden et al. 1990, Woerdenbag et al. 1990, Chattopadhyay et al. 2002, 2003, Lin et al. 2003). The author has also successfully initiated and maintained cell cultures of $P$. hexandrum for several years in their laboratory (Majumder and Jha 2009). The objective of the present study was to improve podophyllotoxin accumulation in cell suspension cultures of $P$. hexandrum through addition of tryptophan, an indirect precursor of lignan biosynthesis.

\section{Materials and Methods}

Cell suspension cultures of four-year-old friable cell line RC4 (Majumder and Jha 2009) were initiated and established in $20 \mathrm{ml}$ liquid P1 medium [half strength B5 basal medium (Gamborg et al. 1968) supplemented with 1\% (w/v) sucrose, 2,4-D $(1 \mathrm{mg} / \mathrm{l}), \mathrm{GA}_{3}(1 \mathrm{mg} / \mathrm{l})$ and $\left.\mathrm{BA}(0.1 \mathrm{mg} / \mathrm{l})\right]$ in $150 \mathrm{ml}$ flasks. Cultures were incubated in dark at $100 \mathrm{rpm}$ on a gyratory shaker at $24 \pm 1^{\circ} \mathrm{C}$ with relative humidity of $55-60 \%$ and subcultured after a period of 14 days by filtering through sterile mesh $(60 \mu \mathrm{m})$ to obtain finely suspended cells. Larger cell aggregates were removed. A volume of $5 \mathrm{ml}$ of inoculum $\left(\sim 10^{4}\right.$ cells $\left./ \mathrm{ml}\right)$ was transferred to $20 \mathrm{ml}$ fresh medium $(1: 4)$ in a $150 \mathrm{ml}$ flask. Cultures were maintained by regular subculturing at two weeks interval. Samples were collected from finely dispersed cell suspension cultures and regularly examined under inverted microscope (Model: LABOVERT, Leitz). Cell density was estimated and monitored by using a hemocytometer.

Different concentrations (100, 250 and $500 \mathrm{mg} / \mathrm{l}$ ) of filter sterilised tryptophan

were added to 14-day-old cell suspension cultures established with four-year-old cell line RC4 as mentioned above and grown at $100 \mathrm{rpm}$ on a gyratory shaker at $24 \pm 1^{\circ} \mathrm{C}$ in the dark with relative humidity of $55-60 \%$. After seven days cultures from each flask were dried $\left(48 \mathrm{hrs}, 45^{\circ} \mathrm{C}\right)$ and weighed after harvesting cells on a Buchner funnel applied with a filter paper for analysis of cell growth and podophyllotoxin content. Growth index (GI) was expressed as a ratio of final and initial dry weights (DW) of the cell masses. Ten replicates were used for each treatment and all experiments were repeated thrice.

Podophyllotoxin was extracted from cultured cells following the method of Heyenga et al. (1990) with modification and analysed by HPLC using standard samples of podophyllotoxin (Sigma). Samples (0.1 - $0.2 \mathrm{gDW})$ were heated with dehydrated ethanol on water bath for $3 \mathrm{hrs}$ after which the ethanol phase was evaporated to dryness. Extracts of cell free medium were prepared by mixing with chloroform $(1: 2)$ and stirred continuously for $3 \mathrm{hrs}$ using a magnetic stirrer. 
The chloroform fractions were separated using a separatory funnel and dried. The dried residues were redissolved in $1 \mathrm{ml}$ analytical grade methanol, filtered (Sartotius filters, $0.22 \mu \mathrm{m}$ ) prior to analysis and analysed by HPLC as reported earlier (Majumder and Jha 2009). For quantitative analysis peak areas were used to calculate the amount of podophyllotoxin present in the cultured cells and these were compared to the standard. The standard sample was used to construct a calibrated graph by plotting peak areas versus amount of podophyllotoxin injected over a range of $5-40 \mu \mathrm{g}$. The relationship was linear over ten measurements. Identification of podophyllotoxin was done by retention time and spiking with standard (Majumder and Jha 2009). Podophyllotoxin was identified by preparative HPLC and identified using ${ }^{1} \mathrm{H}-\mathrm{NMR}$ by comparing with literature values (Jackson and Dewick 1984a).

Data were analysed by ANOVA to detect significant differences between means (Sokal and Rohlf 1987). Means differing significantly were compared using the Duncan (1955) DMRT at the 5\% probability level. Variability around the mean was represented as \pm the standard error.

\section{Results and Discussion}

Growth kinetics of cell suspension culture of RC4 showed a typical growth pattern characteristic of cell suspensions (Fig. 1). Cell counting with hemocytometer revealed that there was rapid growth during the first phase of the growth cycle (day 0 to day 14) followed by an inhibition of growth in the second phase (day 14 to day 21$)$. Maximum cell density $\left(13.4 \pm 0.5 \times 10^{4}\right.$ cells $\left./ \mathrm{ml}\right)$ was noted on day 14 after which there was a sharp decline in cell density (10 \pm 1 $\times 10^{4}$ cells/ml on day 21 ). Thus, tryptophan was added on the 14 th day of the growth cycle and cells harvested seven days later.

The effect of tryptophan on biomass yield and podophyllotoxin accumulation in cell suspension cultures of RC4 was studied. In untreated cell suspensions, podophyllotoxin content was $2.8 \pm 0.5 \mathrm{mg} / \mathrm{gDW}$. Suspension cultures accumulated 2.7 times more podophyllotoxin than untreated control cultures when treated with $250 \mathrm{mg} / \mathrm{l}$ tryptophan (Fig. 2). But higher (500 mg/l) or lower $(100 \mathrm{mg} / \mathrm{l})$ concentrations of tryptophan used could not improve podophyllotoxin accumulation in cell suspension cultures. Podophyllotoxin was not detected in any of the culture media analysed indicating that it was only present intracellularly and not exuded in the culture medium. However, cell growth decreased after the addition of tryptophan. 


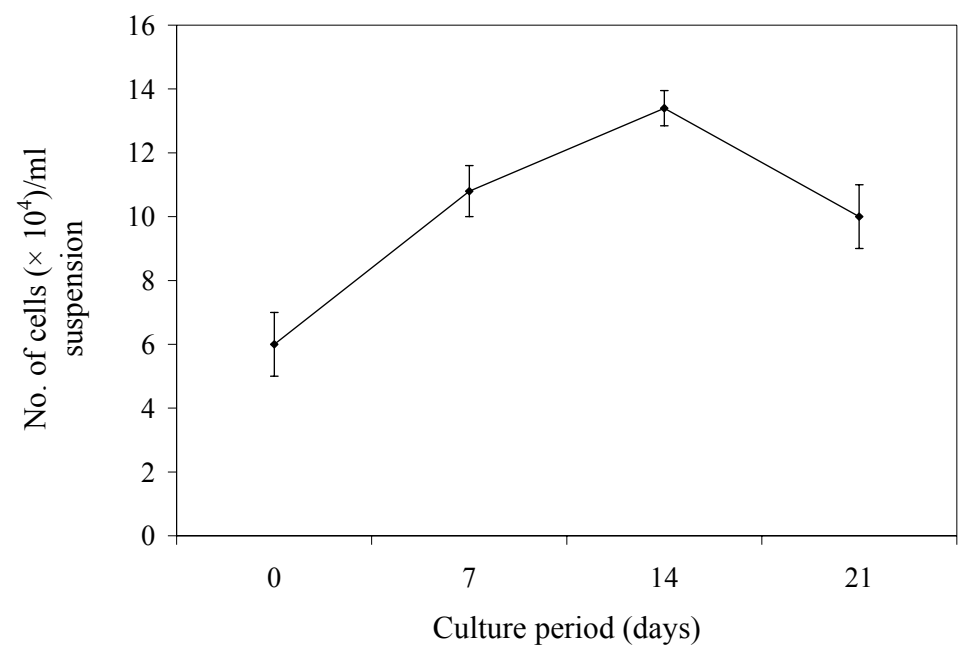

Fig. 1. Growth kinetics of cell line RC4 cultured in $20 \mathrm{ml}$ liquid P1 medium in the dark at $100 \mathrm{rpm}$ at $24 \pm 1^{\circ} \mathrm{C}$ over a period of 21 days. All values are means \pm standard error of three independent experiments $(n=15)$. Inoculum density $\sim 6 \times 10^{4}$ cells $/ \mathrm{ml}$ suspension.

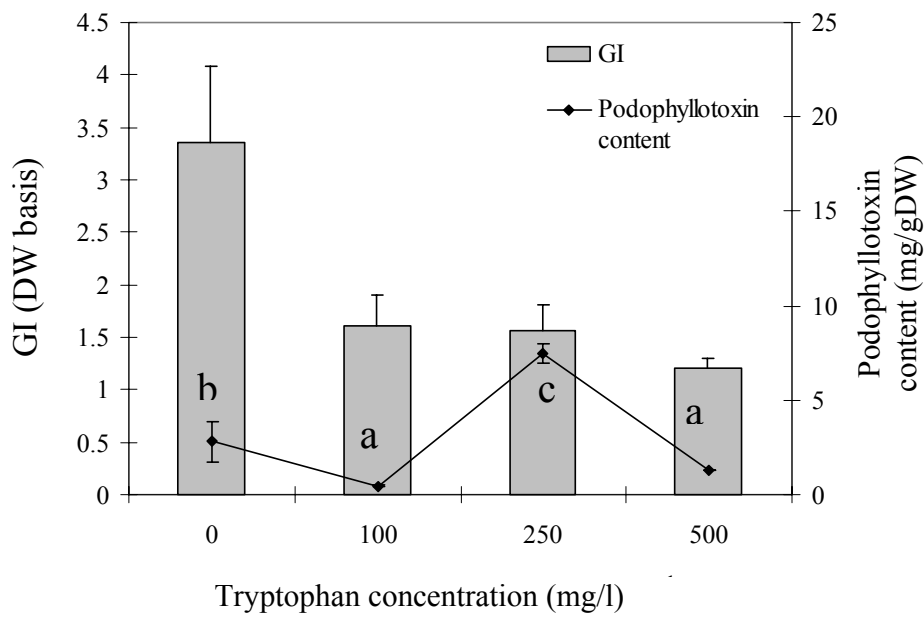

Fig. 2. Effect of tryptophan on biomass yield and podophyllotoxin content in cell suspension cultures of cell line RC4 after a period of 21 days. All values are means \pm standard error of three independent experiments $(n=30)$. Values with different letters are significantly different from each other at $\mathrm{p} \leq 0.05$ according to ANOVA and DMRT.

Exogenous supply of a biosynthetic precursor to the culture medium is an interesting alternative to increase the yield of a desired product; bottlenecks and flux imbalances in biosynthetic pathways are overcome by supplying exogenous compounds that are relatively close to the desired product (Lin et al. 2003). 
Attempts to increase the production of plant secondary metabolites by supplying biosynthetic precursors have been effective in many cases (Fett-Neto et al. 1994, Ghosh et al. 2002, Masoumian et al. 2011, Riedel et al. 2012). Podophyllotoxin, a lignan, is a product of the phenylpropanoid pathway. The biosynthesis of lignans originates from phenylalanine and tyrosine (Ward 1982, Vardapetyan et al. 2003) which are converted via a series of intermediates to coniferyl alcohol, a key precursor in the pathway (Jackson and Dewick 1984b). In the present study, tryptophan, although not a compound from the phenylpropanoid pathway, could improve the accumulation of podohyllotoxin in cell suspension cultures. Tryptophan and phenylalanine/tyrosine are generated from the common precursor chorismate (Maeda and Dudareva 2012), which in turn is produced by the condensation of shikimate with a molecule of phosphoenolpyruvate (Yao et al. 1995). Enzyme chorismate mutase converts chorismate to prephenate which is the first committed step in the synthesis of phenylalaine and tyrosine (Schnappauf et al. 1998). Evidence shows that this enzyme is strongly activated by tryptophan (Schmidheini et al. 1989, 1990, Braus 1991). Thus improvement in podophyllotoxin accumulation in cell suspension cultures might be due to positive feedback activation of phenylalanine and tyrosine biosynthesis by tryptophan (Bentley 1990). Tryptophan can thus been considered as an indirect precursor in the biosynthesis of podophyllotoxin. There is no previous report on the effect of this indirect precursor of lignan biosynthesis on cell suspension cultures of $P$. hexandrum. However, tryptophan adversely affected cell growth. Thus, optimization of a two-stage-culture system for biomass accumulation and podophyllotoxin production might further improve the yield of podophyllotoxin in cell suspension cultures of $P$. hexandrum.

\section{Acknowledgement}

The author thanks Prof. S. Jha, mentor, WOS-A-DST (Women Scientists Scheme of the Department of Science \& Technology, Govt. of India) programme and Programme Coordinator, Centre of Advanced Study, Department of Botany, University of Calcutta for providing facilities. The award of WOS-A by DST is also gratefully acknowledged.

\section{References}

Bentley R (1990) The shikimate pathway - A metabolic tree with many branches. Crit. Rev. Biochem. Mol. Biol. 25: 307-384.

Braus GH (1991) Aromatic amino acid biosynthesis in the yeast Saccharomyces cerevisiae: A model system for the regulation of a eukaryotic biosynthetic pathway. Microbiol. Rev. 55(3): 349-370. 
Chattopadhyay S, Mehra RS, Srivastava AK, Bhojwani SS and Bisaria VS (2003) Effect of major nutrients on podophyllotoxin production in Podophyllum hexandrum suspension cultures. Appl. Microbiol. Biotechnol. 60: 541-546.

Chattopadhyay S, Srivastava AK and Bisaria VS (2002) Optimisation of culture parameters for production of podophyllotoxin in suspension culture of Podophyllum hexandrum. Appl. Biochem. Biotechnol. 102/103: 381-393.

Duncan DB (1955) Multiple range and multiple F-tests. Biometrics 11: 1-42.

Fett-Neto AG, Melanson SJ, Nicholson SA, Pennington JJ and Dicosmo F (1994) Improved taxol yield by aromatic carboxylic acid and amino acid feeding to cell cultures of Taxus cuspidata. Biotechnol. Bioeng. 44: 967-971.

Gamborg OL, Miller RA and Ojima K (1968) Nutrient requirements of suspension cultures of soyabean root cells. Exp. Cell Res. 50: 151-158.

Ghosh B, Mukherjee S, Jha TB and Jha S (2002) Enhanced colchicine production in root cultures of Gloriosa superba by direct and indirect precursors of the biosynthetic pathway. Biotechnol. Lett. 24: 231-234.

Heyenga AG, Lucas JA and Dewick PM (1990) Production of tumour inhibitory lignans in callus culltures of Podophyllum hexandrum. Plant Cell Rep. 9: 382-385.

Holthius JJM (1988) Etoposide and teniposide: Bioanalysis, metabolism and clinical pharmokinetics. Pharm. Weekbl. 10: 101-116.

Imbert TF (1998) Discovery of podophyllotoxins. Biochimie 80: 207-222.

Jackson DE and Dewick PM (1984a) Aryltetralin lignans from Podophyllum hexandrum and Podophyllum peltatum. Phytochemistry 23: 1147-1152.

Jackson DE and Dewick PM (1984b) Biosynthesis of Podophyllum lignans-I. Cinnamic acid precursors of podophyllotoxin in Podophyllum hexandrum. Phytochemistry 3: 10291035.

Kadkade PG (1981) Formation of podophyllotoxin by Podophyllum peltatum tissue cultures. Naturwissenchaften 68: 481-482.

Lin H, Kian HK and Doran PM (2003) Production of podophyllotoxin using cross-species coculture of Linum flavum hairy roots and Podophyllum hexandrum cell suspensions. Biotechnol. Prog. 19: 1417-1426.

Maeda H and Dudareva N (2012) The shikimate pathway and aromatic amino acid biosynthesis in plants. Annu. Rev. Plant Biol. 63: 73-105.

Majumder A and Jha S (2009) Characterization of podophyllotoxin yielding cell lines of Podophyllum hexandrum. Caryologia 62(3): 220-235.

Masoumian M, Arbakariya A, Syahida A and Maziah M (2011) Effect of precursors on flavonoid production by Hydrocotyle bonariensis callus tissues. Afr. J. Biotechnol. 10(32): 6021-6029.

Riedel H, Akumo DN, Saw NMMT, Kütük O, Neubauer P and Smetanska I (2012) Elicitation and precursor feeding influence phenolic acids composition in Vitis vinifera suspension culture. Afr. J. Biotechnol. 11(12): 3000-3008.

Schmidheini T, Sperisen P, Paravicini G, Hütter R and Braus G (1989) A single point mutation results in a constitutively activated and feedback-resistant chorismate mutase of Saccharomyces cerevisiae. J. Bacteriol. 171: 1245-1253. 
Influence of an Indirect Precursor on Podophyllotoxin

Schmidheini T, Mo“sch HU, Evans J N S and Braus G (1990) Yeast allosteric chorismate mutase is locked in the activated state by a single amino acid substitution. Biochemistry 29: 3660-3668.

Schnappauf G, Lipscomb WN and Braus GH (1998) Separation of inhibition and activation of the allosteric yeast chorismate mutase. Proc. Natl. Acad. Sci. USA. 95: 2868-2873

Sokal R and Rohlf FJ (1987) Introduction to Biostatistics, 2nd ed. Freeman WH and Company, New York.

Stahelin HF and Wartburg AV von (1991) The chemical and biological route from podophyllotoxin glucoside to etoposide. Cancer Res. 51: 5-15.

Uden W van, Pras $\mathbf{N}$ and Malingre TM (1990) On the improvement of the podophyllotoxin production by phenylpropanoid precursor feeding to cell cultures of Podophyllum hexandrum Royle. Plant Cell Tiss. Org. Cult. 23: 217-224.

Uden W van, Pras N, Visser JF and Malingre TM (1989) Detection and identification of podophyllotoxin produced by cell cultures derived from Podophyllum hexandrum Royle. Plant Cell Rep. 8: 165-168.

Vardapetyan HR, Kirakosyan AB, Oganesyan AA, Penesyan AR and Alfermann WA (2003) Effect of various elicitors on lignan biosynthesis in callus cultures of Linum austriacum. Russ. J. Plant Physl. 50(3): 297-300.

Ward RS (1982) The synthesis of lignans and neolignans. Chem. Soc. Rev. 11 : 75-125

Woerdenbag HJ, Uden W van, Frijlink HW, Lerk CF, Pras N and Malingre TM (1990) Increased podophyllotoxin production in Podophyllum hexandrum cell suspension cultures after feeding coniferyl alcohol as a $\beta$-cyclodextrin complex. Plant Cell Rep. 9: 97-100.

Yao K, Luca VD and Brisson N (1995) Creation of a metabolic sink for tryptophan alters the phenylpropanoid pathway and the susceptibility of potato to Phytophthora infestans. The Plant Cell 7: 1787-1799. 